\title{
Effect of Support from Lecturers and Host Country Nationals on Cross-Cultural Adjustment among International Students: Evidence from a Malaysian University
}

\author{
Hak Liong Chan*, Abdul Rahman Yaakob and Saizal Pinjaman \\ Faculty of Business, Economics, and Accountancy, Universiti Malaysia Sabah, 88400 Kota Kinabalu, \\ Sabah, Malaysia
}

\begin{abstract}
Pursuing higher education abroad is a golden opportunity for any student's personal development; however, international students' cross-cultural adjustment (CCA) can be onerous in a foreign country. The purpose of this study is to empirically examine the roles of perceived lecturer support and host country national (HCN) support in international students' CCA in three dimensions, i.e. general, academic, and interaction. Adopting the purposive sampling technique, survey data was collected from a sample of 124 first-year international students in a Malaysian university. The results of the partial least squares structural equation modelling analysis showed that both perceived lecturer support and HCN support are influential in international students' general, academic, and interaction adjustment. These findings suggest that higher education institutions should amplify the role of lecturers and HCNs to help international students adjust to the various cultural aspects in Malaysia. This study contributes to the literature by applying the anxiety and uncertainty management theory to validate the influence of support on CCA in the international student context.
\end{abstract}

Keywords: Cross-cultural adjustment, host country nationals, international students, lecturers, Malaysia, support

ARTICLE INFO

Article history:

Received: 18 December 2020

Accepted: 05 April 2021

Published: 30 June 2021

DOI: https://doi.org/10.47836/pjssh.29.2.25

E-mail addresses:

hakliong.chan@ums.edu.my (Hak Liong Chan)

abdrahman.y@ums.edu.my (Abdul Rahman Yaakob)

saizal@ums.edu.my (Saizal Pinjaman)

* Corresponding author

\section{INTRODUCTION}

According to West (2018), the number of international students in higher education quadrupled to five million between 1990 and 2014 and is expected to reach eight million by 2025 . Indeed, pursuing higher education abroad is an opportunity for students to acquire new skills and gain 
unique learning experiences. In addition to learning how to live in different cultures and forming relationships with local communities (Elemo \& Türküm, 2019), individuals studying abroad also develop cross-cultural competence and a global mindset. However, despite the growth of international students around the globe, the fact remains that these students face unpredictable adjustment challenges in their academic and socio-cultural activities (Bender et al., 2019; Elemo \& Türküm, 2019). When international students fail to feel culturally adjusted in the host country, they are unable to adapt to new living conditions, learning environments, and interaction modes (Nguyen et al., 2018). The adjustment of international students is therefore far more daunting than that of domestic students (Bender et al., 2019).

As such, for international students to enjoy the social and economic aspects of the country they study in (Shu et al., 2020), it is crucial for higher education institutions (HEIs) to identify factors that affect these students' cross-cultural adjustment (CCA) so they can provide conducive learning experiences. CCA has been conceptualised as the extent to which individuals are able to deal with a foreign country's new environment and its locals' uncertain behaviours (Black \& Gregersen, 1991). It is a three-dimensional construct consisting of general adjustment, work adjustment, and interaction adjustment. General adjustment involves factors influencing an individual's life overseas, such as food, housing, shopping, healthcare, and cost of living. Work adjustment encompasses the individuals' adjustment to their work responsibilities and working conditions. Interaction adjustment refers to individuals' level of comfort when interacting with host country nationals (HCNs) in both work and non-work domains (Black \& Gregersen, 1991).

Unfortunately, international students have been known to experience loneliness due to limited social support, as they are separated from family members and friends (Andrade, 2006; Baba \& Hosoda, 2014; Chavajay, 2013). Social support is thus a valuable resource that enables students to function and to maintain psychological well-being, especially in stressful situations (Cohen \& Wills, 1985). When international students face cultural adjustment problems, they tend to seek support from both local and non-local groups (Chavajay, 2013; Ng et al., 2017; Ni \& Wang, 2011). For example, prior studies have revealed that an international student's university and family are sources of support that improve his or her CCA (Chai et al., 2020; Cho \& Yu, 2015; Shu et al., 2020). However, these studies generally overlook other forms of social support that international students may benefit from in situations where specific types of support match their adjustment needs (Elemo \& Türküm, 2019).

Moreover, while extant research on international students has investigated their psychological outcomes associated with perceived social support (see Andrade, 2006; Baba \& Hosoda, 2014; Brunsting et al., 2018; Chavajay, 2013; Yusoff, 2012), to 
the researchers' best knowledge, no known study has undertaken an examination of the effects of support from lecturers and host country nationals (HCNs) on the CCA of international students. In fact, scholars have proven that both lecturers (McClure, 2007; Yee et al., 2018) and HCNs (Robinson et al., 2019; Shu et al., 2020) are distinct sources of support that facilitate international students' academic success and social embeddedness. To address this research gap, the present study applied the anxiety and uncertainty management (AUM) theory (see Gudykunst, 1998), which is based on the underlying assumption that minimising an individual's level of anxiety and uncertainty is likely to eventuate effective CCA and intercultural communication (Gudykunst, 1998; Hammer et al., 1998). As international students come from different countries, they would experience adjustment issues that exacerbate anxiety and uncertainty in their new environment. This applies even to international students with geographical or cultural proximity to their home countries (Wen et al., 2018). The AUM theory elucidates that both perceived lecturer support and HCN support help international students decrease these feelings of anxiety and uncertainty as well as increase their awareness of cultural differences to facilitate CCA. Therefore, the potential to reduce anxiety and uncertainty through social support should be explored further within the international student population.

This study chose the setting of Malaysia, as it is a preferred destination in Asia for quality higher education (Stacey, 2019;
Yusoff, 2012). Malaysia is well-known for its diversity in terms of culture, ethnicity, and religion, which forces international students to leave their comfort zones (Mustafa, 2017). In 2019, Malaysia had 127,583 international students, with $30 \%$ of them enrolled in public HEIs and the remaining 70\% enrolled in private HEIs (Stacey, 2019). To orientate international students to study life in Malaysia, HEIs have made collaborative efforts with local authorities to improve infrastructure, logistics, and amenities (Yeoh, 2017). Despite these initiatives, international students are confronted by Malaysians' tendency to stigmatise them based on appearance, given that the majority of foreign students hail from the Middle East, Africa, India, Sri Lanka, Pakistan, and Southeast Asian countries (Mahmud et al., 2010; Yeoh, 2017). Drawing from the AUM theory, when HCNs stereotype international students without considering their cultural and individual differences (Yusoff, 2012), the latter face anxiety and uncertainty that impede their effective CCA. This further implies that students from these regions do not receive sufficient support from the host community in adjusting to Malaysian culture. Hence, international students need to cope with such situations by seeking alternate social support mechanisms (Ni \& Wang, 2011). In response to this, the current study aimed to determine whether support from lecturers and HCNs facilitates the three dimensions of CCA (i.e. general, academic, and interaction) among international students in Malaysia. 


\section{THEORY AND HYPOTHESES DEVELOPMENT}

\section{Perceived Lecturer Support and Cross- Cultural Adjustment}

Lecturers are university teaching members who play a key role in students' learning process (Aymans et al., 2019). They are responsible for guiding students' learning, cultivating an effective learning environment, and influencing students' perceptions of success in their chosen courses (Aymans et al., 2019). In this study, perceived lecturer support is defined as concern, assistance, and friendship provided by lecturers to university students (Azila-Gbettor \& Abiemo, 2020). While previous studies have reported that the main role of lecturers is to foster students' academic achievement and engagement (Farr-Wharton et al., 2018; McClure, 2007), lecturer support has been found to boost the well-being and adjustment of university students as well (Garcia et al., 2015). Lecturers can thus act as representatives of host universities who provide international students with support and enhance students' emotional and psychological outcomes (Cho $\&$ Yu, 2015). Nevertheless, the relationship between perceived lecturer support and CCA is not fully understood in the higher education literature. Hence, it is crucial to first document why this direct relationship exists.

Based on the AUM theory, CCA occurs when international students stay emotionally strong and psychologically satisfied upon successfully managing their anxiety and uncertainty in a different cross-cultural setting (Ni \& Wang, 2011). Towards this end, lecturer support in the form of the lecturer-student relationship can improve students' work habits, class engagement, and positive feelings towards the university (Azila-Gbettor \& Abiemo, 2020; FarrWharton et al., 2018; Quin et al., 2018). Moreover, international students spend most of their time in their universities and would inevitably have regular interactions with lecturers, as supportive lecturers make time to listen to their students' problems ( $\mathrm{Su} \&$ Wood, 2012; Yee et al., 2018). Therefore, lecturers contribute to the CCA of international students by providing social support and verbal encouragement in the face of adversity. For instance, international students in Malaysia often obtain additional information from their lecturers about temporary accommodation and local customs (see Mahmud et al., 2010). Based on these arguments, the following hypotheses were developed:

H1a: Perceived lecturer support has a positive relationship with general adjustment.

H1b: Perceived lecturer support has a positive relationship with academic adjustment.

H1c: Perceived lecturer support has a positive relationship with interaction adjustment.

\section{Host Country National Support and Cross-Cultural Adjustment}

HCNs have been increasingly studied in the context of expatriates' CCA, particularly in terms of their provision of role information 
and social support (Bader, 2017; Chan et al., 2019). Besides expatriates, HCNs also bestow emotional support to other types of visitors (e.g. migrant workers and international students) in dealing with stressful events (Bader, 2017). Despite the fact that the Malaysian government reinforces cultural diversity through internationalisation in HEIs (Mahmud et al., 2010), international students who are socially accepted by their HCN peers show a particularly higher level of cultural adjustment and satisfaction (Chuah \& Singh, 2016). The latter's support is always sought after to facilitate specific practical and informational learning needs related to language and academics (Chuah \& Singh, 2016).

International students, as such, would benefit from building informal networks with HCNs, as such networks go above and beyond social support from lecturers. Scholars (Baba \& Hosoda, 2014; Ng et al., 2017; Robinson et al., 2019; Yusoff, 2012) explain that creating supportive networks and friendships with HCNs is particularly crucial for international students to compensate for the loss of home country social support and to acquire the cultural knowledge necessary to adjust to local customs. To illustrate, since Malaysia is influenced by the Asian culture and Islamic religion (Hofstede, 2001), HCNs typically exhibit the values of collectivism, respect, and limited expression; these are challenging differences for international students to adapt to (Mahmud et al., 2010). Consequently, these students may experience anxiety and uncertainty in adjusting to local Malaysian customs. Reverting to the AUM theory (Gudykunst, 1998, 2005), when HCNs demonstrate positive attitudes towards foreigners, the latter feel comfortable and experience less insecurity (Hammer et al., 1998). Thus, international students who develop supportive networks within the local society would feel less anxious and uncertain in their new environment. Consistent with this, Baba and Hosoda (2014) found that international students who secure HCN support tend to have less acculturative stress and more effective CCA. Based on these arguments, the following hypotheses were formulated:

$\mathrm{H} 2 \mathrm{a}$ : HCN support has a positive relationship with general adjustment.

$\mathrm{H} 2 \mathrm{~b}$ : HCN support has a positive relationship with academic adjustment. $\mathrm{H} 2 \mathrm{c}$ : $\mathrm{HCN}$ support has a positive relationship with interaction adjustment.

\section{METHODS}

\section{Sampling and Data Collection}

The sample of this study comprised firstyear international students from both undergraduate and postgraduate programmes in a public university in East Malaysia. Apart from the three main Malaysian races (Malay, Chinese, and Indian), the East Malaysian states of Sabah and Sarawak are home to indigenous native races such as Iban, Bidayuh, Kadazandusun, and Bajau, indicating greater cultural diversity (Nagaraj et al., 2015). Some of these native groups share strong spiritual ties to nature, which are reflected in their traditions and rituals. 
Their unique traditional social norms are thus likely to heighten foreigners' degree of anxiety and uncertainty.

Given the above, the first year is the most critical for international students in their chosen university, as it is when they encounter various adjustment difficulties that lead to feelings of homesickness and depression (see Clinciu, 2013). For this reason, the present study excluded continuing students who extended their undergraduate education to postgraduate education in Malaysia, since they may already have developed social networks and adapted effectively.

According to the U-Curve of adjustment, when the 'honeymoon' period of coming to a new country fades, international students start to feel homesick, subsequently experiencing 'culture shock'. During this period, they undergo unpredictable psychological changes, also known as 'adjustment'. Once this critical phase is over, they begin to adapt to the new culture and learn how to behave appropriately, described as 'mastery' (Black \& Mendenhall, 1991). Passing through these stages of the CCA process takes approximately six months (Black \& Mendenhall, 1991). Hence, to capture the actual CCA of international students, the criterion for eligible students in this study was that they must have stayed in Malaysia for at least six months.

The list of international students was obtained from the Centre of Data and Information Management of the chosen university. This was the most reliable sampling frame available for data collection.
A total of 590 international students from 34 countries were registered in this university, mostly from China (60.8\%). Many were also from Brunei (12\%), Indonesia (5.3\%), Bangladesh (3.9\%), and Pakistan (2.7\%). The remaining $15.3 \%$ were from the Middle East, Africa, and other Asian countries. The list showed that 241 out of the university's 590 international students were first-year entrants from the February 2019 and September 2019 intakes. Upon confirming the respondents' eligibility using purposive sampling, questionnaires were distributed to all 241 international students via drop-off and electronic methods. Data collection was carried out for six months from November 2019 to April 2020, at the end of which 136 questionnaires were completed and returned. As 12 of them had to be excluded due to invalid data, 124 complete questionnaires were ultimately used for data analysis, yielding a response rate of $51.5 \%$.

\section{Demographic Profile}

Table 1 illustrates the demographic profile of the respondents. The majority of international students were from China (79.8\%), followed by Brunei (8.2\%), Japan (3.4\%), and Thailand (3.4\%). The remaining were from Gabon (1.6\%), Indonesia $(0.8 \%)$, Yemen $(0.8 \%)$, Nigeria $(0.8 \%)$, and Germany $(0.8 \%)$. The number of female respondents $(58.1 \%)$ outweighed their male counterparts $(41.8 \%)$, and most respondents were below the age of $20(69.4 \%)$. Almost all the respondents were pursuing their undergraduate studies (90.3\%), with only a small percentage of 
Table 1

Respondent profile

\begin{tabular}{|c|c|c|}
\hline & Frequency & Percentage (\%) \\
\hline \multicolumn{3}{|c|}{ Country of origin } \\
\hline China & 99 & 79.8 \\
\hline Brunei & 10 & 8.2 \\
\hline Japan & 4 & 3.2 \\
\hline Thailand & 4 & 3.2 \\
\hline Gabon & 2 & 1.6 \\
\hline Indonesia & 1 & 0.8 \\
\hline Yemen & 1 & 0.8 \\
\hline Nigeria & 1 & 0.8 \\
\hline Germany & 1 & 0.8 \\
\hline No response & 1 & 0.8 \\
\hline \multicolumn{3}{|l|}{ Gender } \\
\hline Male & 52 & 41.9 \\
\hline Female & 72 & 58.1 \\
\hline \multicolumn{3}{|l|}{ Age } \\
\hline Below 20 & 86 & 69.4 \\
\hline $21-25$ & 30 & 24.2 \\
\hline $26-30$ & 0 & 0 \\
\hline $31-35$ & 3 & 2.4 \\
\hline $36-40$ & 4 & 3.2 \\
\hline 41 and above & 1 & 0.8 \\
\hline \multicolumn{3}{|c|}{ Level of educational programme } \\
\hline Bachelor & 112 & 90.3 \\
\hline Master & 3 & 2.4 \\
\hline Doctorate & 9 & 7.3 \\
\hline \multicolumn{3}{|c|}{ First experience studying overseas } \\
\hline Yes & 102 & 82.3 \\
\hline No & 22 & 17.7 \\
\hline \multicolumn{3}{|c|}{ Host language fluency } \\
\hline Yes, fluently & 10 & 8.1 \\
\hline Yes, partially & 70 & 56.4 \\
\hline No & 43 & 34.7 \\
\hline No response & 1 & 0.8 \\
\hline
\end{tabular}

them pursuing postgraduate studies at the Master (2.4\%) and Doctorate (2.4\%) levels. A mere $8.1 \%$ of respondents could speak the local language (Malay) well, as they were from Brunei where the main spoken language is also Malay. Nevertheless, more than half $(56.4 \%)$ of the respondents indicated that they could partially converse in the host language.

\section{Measurement Scales}

Realising that the vast majority of international students were from China, the questionnaire for this study was constructed bilingually, i.e. in English and Chinese. Although international students undergo an English proficiency test before being admitted to a university, they still have difficulties in the language due to their limited vocabulary (Malaklolunthu \& Selan, 2011). This problem is normally faced by Asian students in English-speaking countries or countries that use English as the medium of instruction, such as Malaysia (Malaklolunthu \& Selan, 2011). In this case, translating the questionnaire is one of the strategies to increase the response rate for a diverse group of participants (Chai et al., 2020). After developing the questionnaire, a pilot study was conducted on 30 international students (15= English version; $15=$ Chinese version) to ensure that the respondents could understand its instructions and items. The respondents' feedback was subsequently taken into consideration to make minor modifications to the Chinese version. The final version was then verified by a Chinese language expert.

The measures for the constructs in the research model (e.g. perceived lecturer support, HCN support, and CCA) were adapted from previous studies following a thorough literature review. The 12-item scale for perceived lecturer support was derived from Quin et al. (2018) and modified to the context of university students. Students rated items like "My lecturers are fair in dealing with students" and "In this 
university, lecturers treat students with respect" on a five-point Likert scale from (1) strongly disagree to (5) strongly agree.

The measure for HCN support was adopted from Malek et al. (2015). To make the items relevant to international students, the item "My friends/classmates in Malaysia help me take care of my family when I am busy or away" was removed from the scale. The remaining 15 items were rated on a fivepoint Likert scale from (1) strongly disagree to (5) strongly agree. Sample items included "My friends/classmates in Malaysia give me information about local activities" and "My friends/classmates in Malaysia are concerned about my well-being."

$C C A$ is a three-dimensional construct initially developed by Black and Gregersen (1991) and updated by Nguyen et al. (2018) to suit international students. The latter's scale for CCA was adopted, which encompassed seven items on general adjustment, two items on academic adjustment, and four items on interaction adjustment. A sample item for each dimension was "living condition in general", "academic performance standard and expectations", and "socialising with locals outside of university", respectively. All 13 items on the scale were measured on a five-point Likert scale from (1) strongly unadjusted to (5) strongly adjusted.

Control variables were measured as open-ended questions soliciting gender, age, level of education programme, first experience studying overseas, and host language fluency. These demographic variables are recommended as control variables (Yusoff, 2012) as they have been found to influence the CCA of international students (Shu et al., 2020).

\section{Data Analysis Technique}

Partial least squares structural equation modelling (PLS-SEM) was employed to analyse the data. Given its prominence in the higher education literature (Ghasemy et al., 2020), PLS-SEM is deemed as a suitable analytical tool to explore the emerging phenomenon of international students in higher education research (Ghasemy et al., 2020). First, PLS-SEM is used to predict the relationships between the key constructs in a model (Hair et al., 2017), which is in line with the research objective of explaining the relationships between support and CCA among international students. Second, PLSSEM was able to handle the small sample size $(n=124)$ of this research, as it is still exceeded ten times the number of indicators for the most predicted construct (Barclay et al., 1995). All the control variables were also included in the analysis.

\section{RESULTS}

\section{Measurement Model}

The measurement model assesses the internal consistency of the constructs. Internal consistency was determined using composite reliability (CR) and Cronbach's alpha, where the minimum threshold value for both is .70 (Hair et al., 2017). Table 2 shows that both the CR and Cronbach's alpha values of the items in this study exceeded 0.70 . Next, the convergent validity of the constructs was assessed using average 
Table 2

Internal consistency and convergent validity

\begin{tabular}{|c|c|c|c|c|}
\hline Item & Outer loading & $\mathrm{CR}$ & AVE & Cronbach's alpha \\
\hline \multicolumn{5}{|c|}{ Perceived lecturer support } \\
\hline PL1 & .899 & .965 & .697 & .960 \\
\hline PL2 & .857 & & & \\
\hline PL3 & .706 & & & \\
\hline PL4 & .800 & & & \\
\hline PL5 & .853 & & & \\
\hline PL6 & .901 & & & \\
\hline PL7 & .825 & & & \\
\hline PL8 & .867 & & & \\
\hline PL9 & .860 & & & \\
\hline PL10 & .821 & & & \\
\hline PL11 & .737 & & & \\
\hline PL12 & .871 & & & \\
\hline \multicolumn{5}{|c|}{ HCN support } \\
\hline HCN1 & .768 & .971 & .690 & .968 \\
\hline HCN2 & .832 & & & \\
\hline $\mathrm{HCN} 3$ & .778 & & & \\
\hline HCN4 & .833 & & & \\
\hline HCN5 & .816 & & & \\
\hline HCN6 & .791 & & & \\
\hline HCN7 & .790 & & & \\
\hline HCN8 & .866 & & & \\
\hline HCN9 & .793 & & & \\
\hline HCN10 & .845 & & & \\
\hline HCN11 & .904 & & & \\
\hline HCN12 & .855 & & & \\
\hline HCN13 & .879 & & & \\
\hline HCN14 & .866 & & & \\
\hline HCN15 & .831 & & & \\
\hline \multicolumn{5}{|c|}{ General adjustment } \\
\hline GA1 & .855 & .931 & .658 & .913 \\
\hline GA2 & .795 & & & \\
\hline GA3 & .851 & & & \\
\hline GA4 & .859 & & & \\
\hline GA5 & .732 & & & \\
\hline GA6 & .809 & & & \\
\hline GA7 & .763 & & & \\
\hline \multicolumn{5}{|c|}{ Academic adjustment } \\
\hline AA1 & .944 & .933 & .875 & .860 \\
\hline AA2 & .928 & & & \\
\hline \multicolumn{5}{|c|}{ Interaction adjustment } \\
\hline IA1 & .877 & .955 & .843 & .938 \\
\hline IA2 & .936 & & & \\
\hline IA3 & .920 & & & \\
\hline IA4 & .939 & & & \\
\hline
\end{tabular}


variance extracted values (AVE $\geq 0.5)$. The results indicated that all the constructs achieved a high level of reliability and convergent validity.

The HTMT ratio is a novel method to assess discriminant validity. It is suggested that the maximum value should be HTMT. 85 (Kline, 2011) or HTMT.90 (Gold et al., 2001). Table 3 displays that all the construct values were lower than the thresholds of HTMT. $_{85}$ or HTMT. ${ }_{90}$. The results thus ascertained the discriminant validity of the constructs in this study.

\section{Structural Model}

Before assessing the structural model, variance inflation factor (VIF) values were first used to detect multicollinearity among the constructs, particularly between the independent variables (perceived lecturer support and HCN support) and dependent variables (general adjustment, academic adjustment, and interaction adjustment). The VIF values were lower than 5.0 (1.650 and 1.704), which proved that the data did not suffer from multicollinearity issues (Hair et al., 2017).

Employing the bootstrap re-sampling technique (5,000 re-samples), the path coefficients of the hypothesised relationships were evaluated. Table 4 shows that perceived lecturer support had positive relationships with general adjustment $(\beta=.313, t=3.246$, $p=.001)$, academic adjustment $(\beta=.185$,

Table 3

HTMT criterion

\begin{tabular}{lcccc}
\hline & 1 & 2 & 3 & 4 \\
\hline 1. Perceived lecturer support & & & & \\
2. HCN support & 0.645 & & & \\
3. General adjustment & 0.525 & 0.548 & & \\
4. Academic adjustment & 0.510 & 0.626 & 0.657 & \\
5. Interaction adjustment & 0.540 & 0.668 & 0.723 & 0.807 \\
\hline
\end{tabular}

Table 4

Results of path relationships

\begin{tabular}{lccccc}
\hline Hypothesis & Beta & Standard error & $t$-value & $p$-value & Decision \\
\hline $\begin{array}{l}\text { H1a: Perceived lecturer support } \rightarrow \text { General } \\
\text { adjustment }\end{array}$ & .313 & 0.097 & 3.246 & .001 & Supported \\
$\begin{array}{l}\text { H1b: Perceived lecturer support } \rightarrow \\
\text { Academic adjustment }\end{array}$ & .185 & 0.100 & 1.856 & .032 & Supported \\
$\begin{array}{l}\text { H1c: Perceived lecturer support } \rightarrow \\
\text { Interaction adjustment }\end{array}$ & .216 & 0.091 & 2.387 & .009 & Supported \\
H2a: HCN support $\rightarrow$ General adjustment & .369 & 0.085 & 4.332 & .000 & Supported \\
H2b: HCN support $\rightarrow$ Academic adjustment & .466 & 0.087 & 5.343 & .000 & Supported \\
H2c: HCN support $\rightarrow$ Interaction adjustment & .521 & 0.085 & 6.126 & .000 & Supported \\
\hline
\end{tabular}


$t=1.856, p=.032)$, and interaction adjustment $(\beta=.216, t=2.387, p=.009)$. These findings supported H1a, H1b, and H1c. Similarly, HCN support had positive relationships with general adjustment $(\beta=.369, t=4.332, p=.000)$, academic adjustment $(\beta=.466, t=5.343, p=.000)$, and interaction adjustment $(\beta=.521, t=6.126$, $p=.000$ ), thereby confirming $\mathrm{H} 2 \mathrm{a}, \mathrm{H} 2 \mathrm{~b}$, and $\mathrm{H} 2 \mathrm{c}$.

To assess effect size ( $\left.\mathrm{f}^{2}\right)$, Cohen's (1988) guideline was adopted. The analysis results indicated that perceived lecturer support had a small effect on general adjustment (.097), academic adjustment (.034), and interaction adjustment (.054). Meanwhile, HCN support produced a small effect on general adjustment (.130) and a medium effect on academic adjustment (.209) and interaction adjustment (.303). Overall, both sources of support explained $38.5 \%$, $39.1 \%$, and $47.4 \%$ of the variance in general adjustment $\left(\mathrm{R}^{2}=.385\right)$, academic adjustment $\left(\mathrm{R}^{2}=.391\right)$, and interaction adjustment $\left(\mathrm{R}^{2}=.474\right)$, respectively. Of all the control variables, host language fluency $(\beta=$ $.130, t=1.796, p=.037)$ and age $(\beta=-.299$, $t=2.232, p=.013$ ) were found to positively impact general adjustment and academic adjustment, respectively.

The final step of the structural model assessment was to examine the predictive relevance of the model using the blindfolding method. Hair et al. (2017) suggested that a $\mathrm{Q}^{2}$ value greater than zero implies that exogenous variables have predictive relevance for endogenous variables. The $\mathrm{Q}^{2}$ values for general adjustment (.203), academic adjustment (.284), and interaction adjustment (.360) were more than zero, indicating that the model had sufficient predictive relevance.

\section{DISCUSSION}

This research set out to examine the impact of perceived lecturer support and $\mathrm{HCN}$ support on CCA among international students. The results suggest that both sources of support are positively related to the different facets of CCA (general, academic, and interaction). Consistent with the AUM theory (Gudykunst, 1998, 2005), when international students receive support from their lecturers and HCN peers, they are better able to manage the anxiety and uncertainty stemming from studying in a multicultural country like Malaysia.

The findings on perceived lecturer support indicated that when international students believe their lecturers are supportive, they have a smoother time adjusting to the living and learning environments in the host country. This finding is in line with Mahmud et al. (2010), who highlighted that international students in Malaysia can get useful support and information from their lecturers in matters such as temporary housing and cultural knowledge. In addition, upon university admission, all students are assigned an academic mentor or supervisor from their faculty to advise them on general and academic matters. This academic mentor is responsible for monitoring international students' well-being and academic performance. Thus, with respect to academic adjustment, lecturers provide 
equal learning opportunities for international students in Malaysia so they are at par with their local peers (Mahmud et al., 2010). This is further evidenced by the fact that most lectures and tutorials maintain English as the medium of instruction to engage students from different cultural backgrounds. Indeed, since the majority of lecturers in Malaysia speak several languages (Malay, English, and/or Chinese), international students find it easier to communicate with them as there are no significant language barriers. Overall, this finding is noteworthy because it is the first that documents the positive influence of perceived lecturer support on international students' CCA from the perspective of a multicultural country.

The results also revealed that international students who are supported by HCNs feel more adjusted to the cultural dimensions of the host country, which is consistent with other studies on CCA (Baba \& Hosoda, 2014; Bader, 2017). One possible explanation for this finding is the collectivistic nature of the respondents, given that $95.2 \%$ of them were Asians (China, Brunei, and Japan). Hofstede (2001) categorised Asian countries as typically collectivist societies that are attached to a strong sense of group membership. In fact, individuals belonging to a collectivist society heavily rely on their in-group members to strengthen their support system. As Malaysia is high in collectivism (Chan et al., 2019; Malek et al., 2015), HCNs are likely to consider Asian international students as in-group members; consequently, they would have a greater willingness to provide adjustment-related support to these foreign students. For instance, HCNs may support international students in understanding the host university as well as the implicit rules of the local society. HCN peers can also equip international students with information about shopping (e.g. groceries), utilities (e.g. internet), and services (e.g. healthcare), which fosters the general adjustment of these students. Moreover, as communication with HCNs is more informal than with lecturers, international students can discuss their problems with HCN peers in both academic and personal domains. This enables HCNs to grant direct and personal feedback about the behaviours of international students, thus strengthening the latter's academic adjustment and interaction adjustment.

\section{Theoretical and Practical Implications}

This study applied the AUM theory (Gudykunst, 1998, 2005) to explain the rationale behind the influence of social support from lecturers and HCNs on the three dimensions of CCA (general, academic, and interaction) among international students. At this juncture, this research is among the few that have contributed to the existing knowledge on CCA in the higher education setting (Baba \& Hosoda, 2014; Nguyen et al., 2018; Shu et al., 2020) by emphasising the importance of social support (i.e. lecturers and $\mathrm{HCNs}$ ) for international students to minimise CCA problems. Based on the AUM theory, when international students are unfamiliar with the local culture, they encounter a fear of the unknown that deters them from adjusting to their 
new environment. Nevertheless, they can overcome various cross-cultural challenges by seeking support from their lecturers and $\mathrm{HCN}$ peers to reduce their feelings of anxiety and uncertainty. If international students improve their relationships with these individuals, they would be able to effectively adapt to their country of academic pursuit (Ni \& Wang, 2011).

The results of this study carry two practical implications for HEIs in Malaysia. First, motivated by the positive effect of perceived lecturer support on CCA, HEIs should integrate international students into the local community by engaging them in various interactive activities in the university. For example, HEIs should introduce mentor-mentee programmes that reinforce international students' relationships with their lecturers. These programmes allow lecturers to personally advise and guide new international students who have minimal cultural knowledge about the host country. Besides, lecturers should monitor international students' academic progress and provide honest feedback to improve their academic performance (see Azila-Gbettor \& Abiemo, 2020).

Second, since HCN support is influential in international students' CCA and potential success (Robinson et al., 2019), the Student Affairs Department of an HEI plays a key role in encouraging domestic students to help their international counterparts acclimatise to the local culture. For instance, the Department can consider pairing international students with domestic students who are willing to aid their adjustment in living, academic, and interaction domains. This 'buddy' system would bridge the gap between domestic and international students and would be especially useful for first-year international students who feel anxious and uncertain during their initial period of studying in Malaysia (see Chan et al., 2019; Clinciu, 2013).

\section{Limitations and Recommendations for Future Studies}

Despite its implications, the present study experienced three limitations. First and foremost, the findings of this study cannot be generalised because its sample of international students was derived from a single university in East Malaysia, where the majority of them were from China. Consequently, the findings are skewed towards this group of students and cannot ascertain to what extent this sample represents the international student population in Malaysia. To address this, future research should conduct similar studies with larger samples involving other HEIs and international students from different countries. Second, although significant relationships were found between the independent and dependent variables, a questionnaire-based quantitative approach does not adequately depict the CCA process among international students. Future researchers should carry out a follow-up qualitative study to deepen the understanding of social support mechanisms and CCA in the higher education context. Third, this 
study only focused on two types of support (i.e. lecturers and HCNs) as antecedents of CCA without considering the latter's potential effects on aspects such as academic performance and engagement. Hence, a longitudinal study should be undertaken to incorporate the possible outcomes of CCA, which are likely to determine academic success among international students in their subsequent years of study.

\section{CONCLUSION}

Although pursuing higher education abroad is a fulfilling experience for many individuals, it is not without its challenges. Delving into this emerging and important research area, this study extended the AUM theory (Gudykunst, 1998, 2005) to posit that lecturers and HCNs are valuable sources of support who alleviate international students' anxiety and uncertainty due to poor cultural adjustment. The results proved that perceived lecturer support and HCN support positively affect international students' CCA. The practical implications of this study can be used as a guideline by HEIs, academics, and higher education policymakers in Asian countries like Malaysia to enhance international students' learning experiences.

\section{ACKNOWLEDGEMENT}

The authors would like to acknowledge the Research and Innovation Management Centre, Universiti Malaysia Sabah, for funding this research project [Grant No: SPLB0194-2019].

\section{REFERENCES}

Andrade, M. S. (2006). International students in English-speaking universities: Adjustment factors. Journal of Research In International Education, 5(2), 131-154. https://doi. org/10.1177/1475240906065589

Aymans, S. C., Kortsch, T., \& Kauffeld, S. (2019). Gender and career optimism - The effects of gender-specific perceptions of lecturer support, career barriers and self-efficacy on career optimism. Higher Education Quarterly, 74(3), 1-17. https://doi.org/10.1111/hequ.12238

Azila-Gbettor, E. M., \& Abiemo, M. K. (2020). Moderating effect of perceived lecturer support on academic self-efficacy and study engagement: evidence from a Ghanaian university. Journal of Applied Research in Higher Education, ahead-of-print. https://doi.org/10.1108/ JARHE-04-2020-0079

Baba, Y., \& Hosoda, M. (2014). Home away home: Better understanding of the role of social support in predicting cross-cultural adjustment among international students. College Student Journal, 48(1), 1-15.

Bader, A. K. (2017). The effect of host country nationals' social support on expatriates' adjustment - A multiple stakeholder approach. In B. Bader, T. Schuster, \& A. K. Bader (Eds.), Expatriate management: Transatlantic dialogues (pp. 137-163). Springer. https://doi. org/10.1057/978-1-137-57406-0_5

Barclay, D. W., Higgins, C. A., \& Thompson, R. (1995). The Partial Least Squares (PLS) approach to causal modeling: Personal computer adoption and use as an illustration. Technology Studies, 2(2), 285-309.

Bender, M., van Osch, Y., Sleegers, W., \& Ye, M. (2019). Social support benefits psychological adjustment of international students: Evidence from a meta-analysis. Journal of Cross- 
Cultural Psychology, 50(7), 827-847. https:// doi.org/10.1177/0022022119861151

Black, J. S., \& Gregersen, H. B. (1991). Antecedents to cross-cultural adjustment for expatriates in Pacific Rim Assignments. Human Relations, 44(5), 497-515. https://doi. org/10.1177/001872679104400505

Black, J. S., \& Mendenhall, M. (1991). The U-curve adjustment hypothesis revisited: A review and theoretical framework. Journal of International Business Studies, 22(2), 225-247. https://oi. org/10.1057/palgrave.jibs.8490301

Brunsting, N. C., Zachry, C., \& Takeuchi, R. (2018). Predictors of undergraduate international student psychosocial adjustment to US universities: A systematic review from 2009-2018. International Journal of Intercultural Relations, 66, 22-33. https://doi.org/10.1016/j.ijintrel.2018.06.002

Chai, D. S., Van, H. T. M., Wang, C.W., Lee, J., \& Wang, J. (2020). What do international students need? The role of family and community supports for adjustment, engagement, and organisational citizenship behaviour. Journal of International Students, 10(3), 571-589. https:// doi.org/10.32674/jis.v10i3.1235

Chan, H. L., Zawawi, D., \& Ng, S. I. (2019). Effects of primary stakeholders' support on expatriate adjustment and performance in Malaysia. Jurnal Pengurusan, 56, 3-14. https://doi.org/10.17576/ pengurusan-2019-56-01

Chavajay, P. (2013). Perceived social support among international students at a U.S. university. Psychological Reports: Sociocultural Issues in Psychology, 112(2), 667-677. https://doi. org/10.2466/17.21.PR0.112.2.667-677

Cho, J., \& Yu, H. (2015). Roles of university support for international students in the United States: Analysis of a systematic model of university identification, university support, and psychological well-being. Journal of Studies in
International Education, 19(1), 11-27. https:// doi.org/10.1177/1028315314533606

Chuah, J. S., \& Singh, M. K. (2016). International students' perspectives on the importance of obtaining social support from host national students. International Education Studies, 9(4), 132-140.

Clinciu, A. I. (2013). Adaptation and stress for the first year university students. Procedia - Social and Behavioural Sciences, 78, 718-722. https://doi. org/10.1016/j.sbspro.2013.04.382

Cohen, J. (1988). Statistical power analysis for the behavioural science (2nd ed.). Lawrence Erlbaum Associates.

Cohen, S., \& Wills, T. A. (1985). Stress, social support and the buffering hypothesis. Psychological Bulletin, 98(2), 310-357. https:// doi.org/10.1037/0033-2909.98.2.310

Elemo, A. S., \& Türküm, A. S. (2019). The effects of psychoeducational intervention on the adjustment, coping self-efficacy and psychological distress levels of international students in Turkey. International Journal of Intercultural Relations, 70, 7-18. https://doi. org/10.1016/j.ijintrel.2019.02.003

Farr-Wharton, B., Charles, M. B., Keast, R., Woolcott, G., \& Chamberlain, D. (2018). Why lecturers still matter: The impact of lecturer-student exchange on student engagement and intention to leave university prematurely. Higher Education, 75, 167-185. https://doi.org/10.1007/s10734-0170190-5

Garcia, P. R. J. M., Restubog, S. L. D., Bordia, P., Bordia, S., \& Roxas, R. E. O. (2015). Career optimism: The roles of contextual support and career decision-making self-efficacy. Journal of Vocational Behaviour, 88, 10-18. https://doi. org/10.1016/j.jvb.2015.02.004

Ghasemy, M., Teeroovengadum, V., Becker, J. M., \& Ringle, C. M. (2020). This fast car can move 
faster: a review of PLS-SEM application in higher education research. Higher Education, 80(6), 1121-1152.

Gold, A. H., Malhotra, A., \& Segars, A. H. (2001). Knowledge management: An organisational capabilities perspective. Journal of Management Information Systems, 18(1), 185-214. https://doi. org/10.1080/07421222.2001.11045669

Gudykunst, W. B. (1998). Applying anxiety/ uncertainty management (AUM) Theory to intercultural adjustment training. International Journal of Intercultural Relations, 22(2), 227-250. https://doi.org/10.1016/S01471767(98)00005-4

Gudykunst, W. B. (Ed.) (2005). Theorising about intercultural communication. Sage Publications.

Hair, J. F., Sarstedt, M., Ringle, C. M., \& Gudergan, S. P. (2017). Advanced issues in Partial Least Squares Structural Equation Modeling. Sage Publications.

Hammer, M. R., Wiseman, R. L., Rasmussen, J. L., \& Bruschke, J. C. (1998). A test of anxiety/uncertainty management theory: The intercultural adaptation context. Communication Quarterly, 46(3), 309-326. https://doi. org/10.1080/01463379809370104

Hofstede, G. (2001). Culture's consequences: Comparing values, behaviours, institutions and organisations across nations. Sage Publications.

Kline, R. B. (2011). Convergence of structural equation modeling and multilevel modeling. In M. Williams \& W. P. Vogt (Eds.), Handbook of methodological innovation in social research methods (pp. 562-589). Sage Publications.

Mahmud, Z., Amat, S., Rahman, S., \& Ishak, N. M. (2010). Challenges for international students in Malaysia: Culture, climate and care. ProcediaSocial and Behavioural Sciences, 7, 289-293. https://doi.org/10.1016/j.sbspro.2010.10.040
Malaklolunthu, S., \& Selan, P. S. (2011). Adjustment problems among international students in Malaysian private higher education institutions. Procedia - Social and Behavioural Sciences, 15,833-837. https://doi.org/10.1016/j. sbspro.2011.03.194

Malek, M. A., Budhwar, P., \& Reiche, B. S. (2015). Sources of support and expatriation: A multiple stakeholder perspective of expatriate adjustment and performance in Malaysia. The International Journal of Human Resource Management, 26(2), 258-276. https://doi.org/10.1080/09585192.201 4.937968

McClure, J. W. (2007). International graduates' cross-cultural adjustment: Experiences, coping strategies, and suggested programmatic responses. Teaching in Higher Education, 12(2), 199-217. https://doi.org/10.1080/13562510701191976

Mustafa, Z. (2017, September 27). International students and the education Malaysia brand. New Straits Times. https://www.nst.com.my/ education/2017/09/284694/internationalstudents-and-education-malaysia-brand

Nagaraj, S., Nai-Peng, T., Chiu-Wan, N., Kiong-Hock, L., \& Pala, J. (2015). Counting ethnicity in Malaysia: The complexity of measuring diversity. In P. Simon, V. Piché, \& A. A. Gagnon, Social statistics and ethnic diversity (pp. 143-173). Cham, Springer. https://doi.org/10.1007/978-3319-20095-8_8

Ng, T. K., Wang, K. W., \& Chan, W. (2017). Acculturation and cross-cultural adaptation: The moderating role of social support. International Journal of Intercultural Relations, 59, 19-30. https://doi.org/10.1016/j.ijintrel.2017.04.012

Nguyen, A.-M. D., Jefferies, J., \& Rojas, B. (2018). Short term, big impact? Changes in self-efficacy and cultural intelligence, and the adjustment of multicultural and monocultural students abroad. International Journal of Intercultural 
Relations, 66, 119-129. https://doi.org/10.1016/j. ijintrel.2018.08.001

Ni, L., \& Wang, Q. (2011). Anxiety and uncertainty management in an intercultural setting: The impact on organisation-public relationships. Journal of Public Relations Research, 23(3), 269-301. https://doi.org/10.1080/106272 6X.2011.582205

Quin, D., Heerde, J. A., \& Toumbourou, J. W. (2018). Teacher support within an ecological model of adolescent development: Predictors of school engagement. Journal of School Psychology, 69, 1-15. https://doi.org/10.1016/j.jsp.2018.04.003

Robinson, O., Somerville, K., \& Walsworth, S. (2019). Understanding friendship formation between international and host-national students in a Canadian university. Journal of International and Intercultural Communication, 13(1), 49-70. https://doi.org/10.1080/17513057.2019.1609067

Shu, F., Ahmed, S. F., Pickett, M. L., Ayman, R., \& McAbee, S. T. (2020). Social support perceptions, network characteristics, and international student adjustment. International Journal of Intercultural Relations, 74, 136-148. https://doi.org/10.1016/j.ijintrel.2019.11.002

Su, F., \& Wood, M. (2012). What makes a good university lecturer? Students' perceptions of teaching excellence. Journal of Applied Research in Higher Education, 4(2), 142-155. https://doi. org/10.1108/17581181211273110
Stacey, V. (2019, September 27). Malaysia to recalibrate its strategy as $200 \mathrm{k}$ int'l student target by 2020 looks unlikely. The Professional in International Education News. https:// thepienews.com/news/malaysia-to-recalibratestrategy-as-200000-target-looks-out-of-reach/

Wen, W., Hu, D., \& Hap, J. (2018). International students' experiences in China: Does the planned reverse mobility work? International Journal of Educational Development, 61, 204-212. https:// doi.org/10.1016/j.ijedudev.2017.03.004

West, J. (2018, February 9). Growth of international student numbers in higher education. QS Quacquarelli. https://www.qs.com/growthinternational-students-higher-education/

Yee, C. P., Yean, T. S., Yi, J., \& Kam, A. (2018). Verifying international students' satisfaction framework for the development of MISSModel in Malaysia. Pertanika Journal of Social Sciences and Humanities, 26(S), 1-18.

Yeoh, O. C. (2017, March 1). Bringing in more quality international students. New Straits Times. https:/www.nst.com.my/news/2017/03/216542/ bringing-more-quality-international-students

Yusoff, Y. M. (2012). Self-efficacy, perceived social support, and psychological adjustment in international undergraduate students in a public higher education institution in Malaysia. Journal of Studies in International Education, 16(4), 353371. https://doi.org/10.1177/1028315311408914 
